\title{
Informação em ciência e tecnologia: políticas, programas e ações governamentais - uma revisão de literatura
}

\begin{abstract}
Marta Lígia Pomim Valentim
D outora em C iência da Informação e D ocumentação pela ECA/U SP. A utora do livro $O$ C usto da I nformação T ecnológica. $O$ rganizadora e uma das autoras do livro A Formação do Profissional da Informação; organizadora e uma das autoras do livro 0 Profissional da I nformação. Líder do grupo de pesquisa "I nterfaces: I nformação e C onhecimento". D ocente da U niversidade Estadual de Londrina. Presidente da A ssociação Brasileira de Educação em Ciência da Informação (A becin), gestão 2001-2004. A tuou como coordenadoradeI nformação Tecnológica na Indústria M etal Leve S/A durante oito anos.

E-mail: valentim@uel
\end{abstract}

\section{Resumo}

Políticas, programas e ações governamentais para 0 desenvolvimento de ciência e tecnologia no país são sistematicamente criadas pelo governo brasileiro, desde a década de 50. No entanto, apesar das várias iniciativas, o estabelecimento de uma infra-estrutura para a sistematização da informação depende essencialmente de financiamento, bem como do interesse da iniciativa privada, no sentido de buscar estes recursos e estabelecer efetivamente no país um novo segmento produtivo denominado indústria da informação.

\section{Palavras-chave}

Política de Informação; Informação em C\&T; Sociedade da Informação; Indústria da Informação.

Information in science and technology: policies, programs and government actions - a literature review

\begin{abstract}
Politics, programs and government actions for the development of science and technology in the country, they are created systematically by the Brazilian government, since the fifties.

However, in spite of the several initiatives, the establishment of an infrastructure for the systematization of the information depends essentially on financing, as well as of the interest of the private initiative, in the sense of looking for these resources and, to establish indeed, a new productive segment in the country denominated of information industry.
\end{abstract}

Keywords

Information policy; Information in science and technology; Information society; Information Industry.
Resgatando a história brasileira ea política voltada para o desenvolvimento de ciência etecnologia $(C \& T)$, verifica-se que muitos governos se preocuparam com essa questão, criando instrumentos quefomentavam o desenvolvimento científico etecnológico no país.

Essa constatação éimportante na medida em que o desenvolvimento da $C \& T$ é insumo para o desenvolvimento econômico do país. A informação sempreinserida nesse contexto, por meio de programas eações específicas, tem tido importantepapel em relação à construção do saber e do fazer ciência. N o entanto, as iniciativas governamentais deveriam ser mais agressivas no que diz respeito àinformação.

M arques afirma: “ $N$ o início da segunda administração Vargas (1951-54), são editadas importantes medidas visando àcriação de condições internas para o desenvolvimento endógeno de tecnologia. $D$ emonstrando estar bem assessorado a respeito da dinâmica própria da $C \& T, G e$ túlio Vargas institui o C N Pq com o propósito inicial de equiparar o Brasil a outras nações desenvolvidas, sobretudo nas questões relacionadas a pesquisas em energia nuclear" (1994, p.21).

$\mathrm{N}$ a gestão Vargas, também é criada a $\mathrm{C}$ oordenação de A perfeiçoamento de Pessoal deN ível Superior (C apes), com o objetivo de "assegurar a existência de um quadro detécnicos, cientistas e humanistas suficiente para atender às necessidades dos empreendimentos públicos eprivados que visam ao desenvolvimento econômico e cultural da N ação" ${ }^{1}$ (1994, p.21).

N os governos $C$ afé $F$ ilho, J uscelino Kubitschek eJ ânio $Q$ uadros, houve, de certaforma, uma estagnação nas políticas voltadas para $C \& T$, assim como dos recursos financeiros. A situação política do país durante o governo deJ oão G oulart agrava o problema, uma vez quehouveêxodo decientistas brasileiros. A situação piora quando $\mathrm{C}$ astelo Branco assume, pois havia nitidamentefalta de respeito pelo trabal ho científico, além das perseguições políticas ${ }^{1}$ (1994. p.22-23). 
Informação em ciência e tecnologia: políticas, programas e ações governamentais - uma revisão de literatura

A política econômicaganha espaço no G overno C ostae Silva, e é desenvolvido o ProgramaE stratégico de D esenvolvimento (PED). Várias ações envolvem o Programa, entre as quais uma política científica e tecnológica para o país ${ }^{1}$ (1994, p.27-28).

$\mathrm{N}$ os governos $\mathrm{M}$ édici e G eisel, dá-se atenção especial ao desenvolvimento científico etecnológico, formulando umapolítica de $C \& T$ expostaem dois documentos: o I e II Plano $\mathrm{N}$ acional de D esenvolvimento (PN D) eo I ell Plano Básico de D esenvolvimento Científico e Tecnológico (PBDCT).

N o G overno F igueiredo, ao contrário das duas últimas administrações públicas, "as questões de ciência e tecnologia são tratadas lacônica e criptograficamente" 1 (1994, p.32).

Q uando J oséSarney assumea Presidência da República, criao M inistério deC iênciaeTecnologia(MCT). O MCT, desdeentão, tem tido uma atuação fundamental para o desenvolvimento da ciência e da tecnologia no Brasil, criando programas eações defomento paraaárea.

Vieira² expõe que os Sistemas Estaduais de I nformação C ientífica e Tecnológica(SEIC T), criados em 1984, tiveram uma reestruturação em 1996 eforam estabelecidos com os seguintes objetivos:

- "disponibilizar informações para o setor produtivo;

- contribuir para asistematização earticulação da oferta de informações em $C \& T$, hoje pulverizada em diversas fontes;

- gerar ponteiros referenciais a informações em C \& T existentes nos estados;

- integrar os sistemas estaduais à RedeA ntares, por meio dadisponibilização de bases dedados;

- propiciar a elaboração de indicadores em C\&T;

- contribuir paraas atividades de planejamento deC \& T no âmbito federal e estadual;

- capacitação de recursos humanos parasuas atividades" (1999, p.175).

Todos os objetivos anteriormente citados são de extrema importância para a consolidação de uma política de $C \& T$ eficaz. 0 primeiro eo segundo objetivos são, respectivamente, "disponibilizar informações para o setor produtivo" e "contribuir para a sistematização e articulação da oferta de informações em C \& T, hoje pulverizada em diversas fontes", chamam a atenção justamente por serem objeto desteartigo.

0 desenvolvimento tecnológico imprimeum ritmo forte aos diversos setores da economia brasileira. A sáreas que precisam desenvolver-se tecnologicamentebuscam insistentementeinformações paradigerir, entender, aplicar emelhorar suas próprias tecnologias.

$\mathrm{N}$ aárea industrial, por exemplo, somente as indústrias que estiverem sintonizadas com as mudanças tecnológicas einseridas em novos paradigmas de gestão sobreviverão às turbulências econômicas queacontecem no mundo.

A indústriabrasileiratem-seesforçado paraacompanhar o desenvolvimento tecnológico internacional e, em algumas áreas, vem conseguindo superar seus concorrentes internacionais, o quecomprova queuma boa gestão tecnológica pode defato colocar essas indústrias em patamar idêntico ao das indústrias estrangeiras.

A s indústrias que investem em pesquisa e desenvolvimento $(P \& D)$ têm patenteado com maior freqüência novos produtos, materiais eprocessos, apesar de, no caso do Brasil, não terem "amesma conotação de 'resultado' do esforço inovativo que têm nos países desenvolvidos" ${ }^{3}$ (1990, p.29). Investir em P\& D industrial éfundamental quando a empresa pretendefazer uma boagestão industrial, isto é, ser competitivanessemercado globalizado.

N o Brasil, sistematicamenteo índice percentual aplicado em $P \& D$ pelaindústriabrasileira é menor do queo índice percentual aplicado pelo governo. A tualmente as indústrias investem em torno de $37,6 \%$ (figura 1, a seguir), enquanto o investimento governamental é de $62,5 \%$. Existe a necessidade de o setor privado investir de maneira mais agressiva em ciência e tecnologia, assim como em $P \& D$ industrial.

"O síndices de aplicação em C \& T pelo Brasil, embora condizentes com uma economia em desenvolvimento, são baixos. $N$ ão pareceser estaumaárea de investimentos prioritários do Estado. Em 1988, os gastos com ciênciae tecnologia reduziram-se para 3\% do 0 rçamento da U nião, ao contrário do queocorreu de 1980 a 1987, quando, praticamente, dobraram, passando de 2,12\% para $3.99 \%$ do 0 rçamento da U nião" ${ }^{4}$ (1992, p.15). 
Em 1995, Rangel afirmava: "É necessário elevar os gastos em $C \& T$ de $0,7 \%$ do PIB paraalgo em torno de 2,0\%, como ocorrenos países desenvolvidos" 5 ( 1995, p.9). 0 s gastos com $C \& T$ alcançaram em torno de 1,2\% do PIB em 1999 (figura 2 ), se somados os investimentos governamentais e o da iniciativa privada.

Weiss ${ }^{6}$, analisando as tendências internacionais, observava:

"V irtualmente to dos os países avançados possuem políticas públicas destinadas aestimular os gastos privados em pesquisa. Em diferentes graus, os governos participam diretamente na pesquisa científica e provêem incentivos e financiamentos para projetos privados de $P \& D "(1995, p .20)$.

N o Plano Plurianual 1996/1999 (PPA) do governo constava exatamenteisso:

"Os investimentos em ciência e tecnologia constituem componente fundamental no desenvolvimento econômico esocial do país, não obstanteos gastos em ciência e tecnologia terem sido historicamentebaixos, em torno de 0,7\% do PIB, nível inferior aos dos países desenvolvidos ou de níveis de desenvolvimento semelhantes ao nosso [...] Pretende-se el evar os gastos nacionais em $C \& T$ para o patamar de $1,5 \%$ do PIB , com uma participação do setor privado de $30 \%$ a 40\%. Paratanto, será fundamental a participação dos governos estaduais e outros segmentos dasociedade, como empresários, trabal hadores ecomunidade científica, bem como 0 aporte derecursos externos, mediante empréstimos einvestimentos diretos"7 (2002).

$\mathrm{N}$ o caso das indústrias privadas brasileiras, somente uma minoria investe em $P \& D$, buscando maior competitividade empresarial. Essa 'cultura' de não praticar $P \& D$ faz com que aqual idadee, conseqüentemente, a rentabilidade e competitividade sejam inferiores às das concorrentes internacionais.

\section{FIGURA 1}

FIGURA 2 contagem.

\section{E sforços em C iência e Tecnologia ( $C \& T$ ) \\ D ispêndios em Pesquisa e D esenvolvimento (P\&D) \\ D ados Preliminares - 1999}

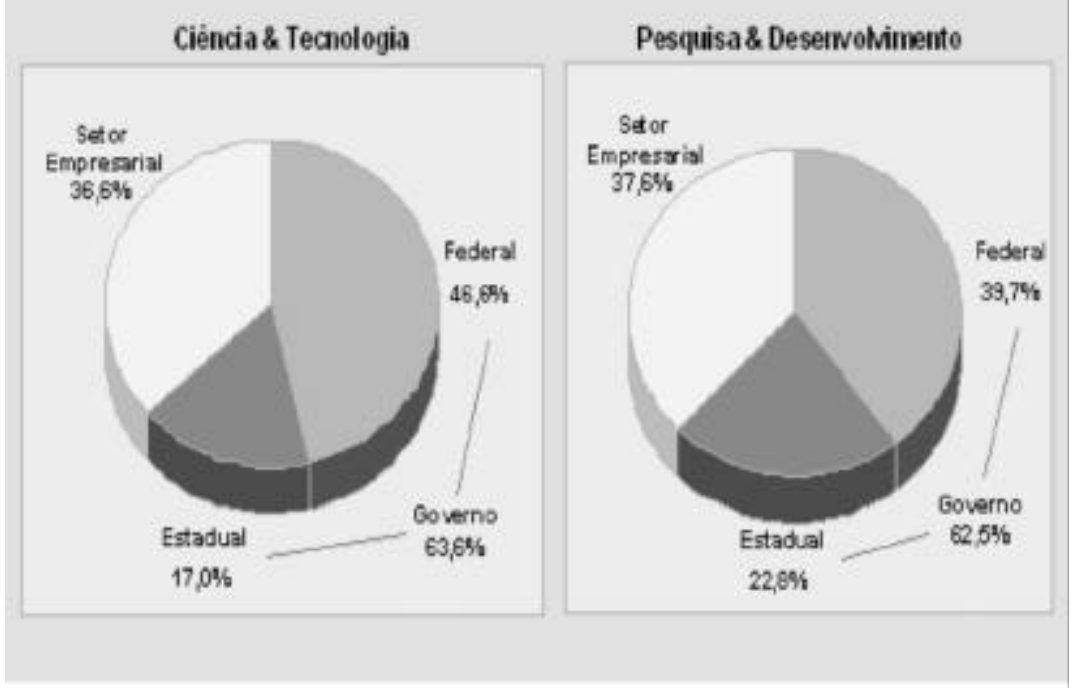

\section{B rasil: E sforços em C iência e Tecnologia ( $C \& T$ ) D ispêndios em Pesquisa e D esenvolvimento ( $P \& D$ ) D ados Preliminares, 1999}

Em RS 1.000.000 de 1999

\begin{tabular}{|c|c|c|c|c|c|c|}
\hline & \multicolumn{3}{|c|}{$\begin{array}{c}\text { Ciència e Tecnologia } \\
\text { (C\&T) }\end{array}$} & \multicolumn{3}{|c|}{$\begin{array}{l}\text { Penquisa e Desenwolviments } \\
\text { (T\&D) }\end{array}$} \\
\hline & Valores & $\begin{array}{c}\text { Distr. } \\
\text { Relativa } \\
(\%)\end{array}$ & $\%$ PIB & Valores & $\begin{array}{c}\text { Distr. } \\
\text { Relativa } \\
(\%)\end{array}$ & $\%$ PIB \\
\hline Total Governo Federal & 6.051 .7 & 46.6 & 0,63 & $3.330,9$ & 39.7 & 0,35 \\
\hline Total Setor Empresarial & $4.757,6$ & 36,6 & 0,50 & $3.153,2$ & 37,6 & 0,33 \\
\hline
\end{tabular}

Fontes: as fontes est 30 discriminadas nas tabelas referenciadas nas linhas da tabela acima Elaboraçāo: Coondenação de Estatisticas e Indicadores - Ministénio da Ciência e Tecnologia Notas as notas estão discrimiradas na Nota Especifica abaixo e nas tabelas referenciadas nas linhas da tabela acima.

A soma das parcelas das distribuiçōes absoluta e relativa dos dispéndios $\mathrm{cm}$ CE T não corresponde exatamente as total, pois foi excluido deste o montante de R\$33.700.000 [trinta e très milhōcs e setecentos mil Reais), correspondente a renúncia fiscal referente a Lei 8.66193, para cvitar dupla

Para que as indústrias brasileiras se capacitem tecnologicamente, énecessário quetenham acesso auma grande quantidade de informações, organizadas, tratadas eacessadas de acordo com sua necessidade. Furtado ${ }^{8}$ também acreditava ser imprescindível "a acumulação de diversos tipos de conhecimento tecnológico para o dinamismo das empresas" (1994, p.9).

0 papel do governo éfundamental paraqueaindústria nacional cresça e tenha competitividade nesse mercado cada vez mais globalizado. D essaforma, a Política N acio- 
Informação em ciência e tecnologia: políticas, programas e ações governamentais - uma revisão de literatura

nal de C iênciae TecnologiaeaPolítical ndustrial devem promover essasensibilização dos empresários brasileiros, apoiando com financiamentos significativos o desenvolvimento tecnológico, seja de produtos e processos industriais, seja de serviços, de uma maneirageral.

"A política brasileira de ciência etecnologiajamais contou com o leque deestímulos fiscais/financeiros tradicionalmente colocados à disposição do desenvolvimento da indústria" ${ }^{9}$ (1997, p.123).

A Política $\mathrm{N}$ acional de $\mathrm{C}$ iênciae Tecnologiavem desenvolvendo al gumas iniciativas de incentivo à $P \& D$, porém são iniciativas muito tímidas, se admitirmos queo empresário brasileiro, na sua maioria, ainda está sesensibilizando para areal necessidade de investimento nessaárea.

"N o Brasil, o setor público constitui-sena principal fonte derecursos para $\mathrm{C} \& \mathrm{~T}$, responsável por cerca de $80 \%$ dos dispêndios nesta área. C om o desequilíbrio financeiro do setor público, observa-sea paulatina redução dos orçamentos para C \& T com progressivo enfraquecimento político e financeiro da infra-estrutura parapesquisa científica e tecnológica montada nos anos 70" 10 ( 1995, p.128). Situação apresentada em 1995, mas que permanece inalterada, isto é, atualmente os dispêndios, conforme mencionado anteriormente, estão na ordem de $70 \% "$.

N avisão deBastos ${ }^{9}$,

“T endo em vista a ausência de políticas explícitas para o desenvolvimento científico etecnológico, afragilidade e volatilidade dos incentivos fiscais criados paraa tecnologia industrial, ea "não-explicitação" de recursos de financiamento para os programas criados pelas políticas industriais recentes, ou mesmo as dificuldades burocráticas existentes para suautilização pelas empresas, pode-se deduzir que a quase totalidade dos instrumentos à disposição das políticas de $C \& T$ e de formação de recursos humanos está inserida nas linhas de financiamento e programas administrados por instituições vinculadas ao M CT eao M EC , mais especificamente a Finep, o CN Pq e a C apes, que cuidam da implementação e execução de programas como 0 PADCT, o RHAE eo FN D CT" (1997, p.124).

\section{C outinho eF erraz ${ }^{10}$ afirmam:}

"Seis macrodiretrizes destacam-se como pontosfundamentais para a superação da fragilidade tecnológica e ausência de cooperação no sistema de inovação brasilei- ro: [...] implantar um sistemaparaaidentificação deoportunidades científicas e tecnológicas e apoiar a montagem eo reforço de programas que garantam arápida disseminação de informações científicas etecnológicas, a ef etiva difusão dos conhecimentos e tecnologias de interessedo setor produtivo; a disseminação das possibilidades reais de resposta da competência técnico/científica instal ada no país aos problemas da produção" (1995, p.143).

Entreas iniciativas deâmbito nacional, pode-se citar o Fundo $\mathrm{N}$ acional de $\mathrm{D}$ esenvolvimento $\mathrm{C}$ ientífico e Tecnológico (F N D C T), criado em 1969, principal fundo de financiamento à infra-estrutura de ciência e tecnologiabrasileira, aF inanciadora deEstudos eProjetos ( F inep), que passou a exercer a Secretaria Executiva do F undo, em $1971^{10}$ (1995, p.128) e $\mathrm{e}^{11}$ (1994, p.127).

O ProgramadeA poio ao $D$ esenvolvimento $C$ ientífico eTecnológico (PADCT), que começou a funcionar em 1984, tem como objetivo "ampliar, melhorar econsolidar a competência técnico-científica nacional no âmbito de universidades, centros de pesquisa eempresas, mediante financiamento de projetos integrados" 12 (1993, p.47).

O programafoi "constituído a partir de uma negociação entre o governo eo Banco M undial [...] e apoiou entre 1985 e 1991 cerca de 2.700 projetos [...] tendo desembolsado U S\$ 179 milhões" ${ }^{11}$ (1994, p.88-90).

A tualmente, o PA D CT III buscamelhorar o "desempenho do setor brasileiro de $C \& T$ com a realização de atividades que promovam a transformação do sistema de $C \& T$ em um sistema eficiente para inovação e/ ou adaptação de tecnologia [...] investindo em: a) atividades de desenvolvimento detecnologia...; b) atividades de pesquisa científica...; c) atividades de suporte setorial..." ${ }^{13}$ (2002).

O PADCT é sem dúvida um dos programas governamentais que pode ser utilizado para o financiamento de bases de dados, portais de informação etc., porquanto uma das atividades que dizem respeito à sua competênciaéo "aperfeiçoamento da infra-estrutura de apoio ede serviços essenciais ao bom desempenho das atividades deC \& T em todo o país" ${ }^{12}$ (1993, p.47). Entretanto, apesar de o programa ser estruturado em vários subprogramas, nenhum deles está especificamente direcionado àconsolidação de dados ou informações produzidas no país. 


\section{Marta Lígia Pomim Valentim}

Em 1951, foi fundado o C onselho $\mathrm{N}$ acional de $D$ esenvolvimento C ientífico eTecnológico (C N Pq) que tem como missão:

"promover e fomentar o desenvolvimento científico e tecnológico do país econtribuir na formulação das políticas nacionais de ciência e tecnologia. Para o cumprimento de sua missão, o C N Pq real iza duas atividades básicas: fomento à pesquisa e formação de recursos humanos voltados para as atividades de C \& T" ${ }^{14}$ (2002).

\section{A Finep, criada há 30 anos,}

"fomenta o desenvolvimento de tecnologias e apóia a sua utilização para atender às necessidades da sociedade brasileira. Paraisso, trabalhaem parceriacom empresas, institutos e centros de pesquisas, outros organismos governamentais, agências multilaterais internacionais, investidores e com entidades do Terceiro Setor. Busca obter resultados econômicos esociais a partir da pesquisae de serviços voltados à inovação, fo mentando o seu pleno desenvolvimento até sua adoção pelos usuários e ações baseadas na inovação como fator de desenvolvimento econômico e social"15 (2002).

A tualmente, o fomento realizado por meio da F inep está direcionado a 13 diferentes F undos Setoriais, "com vistas à captação de recursos para o financiamento de projetos e programas de desenvolvimento científico e tecnológico", como, por exemplo:

- CT-PETRO - Fundo dePetróleo e Gás N atural;

- CT-IN FRA - Fundo deInfra-Estrutura;

- CT-EN ERG - Fundo deEnergia;

- CT-HIDRO - Fundo de Recursos H ídricos;

- CT-TRA N SPO - Fundo deTransportes;

- CT-MINERA L - F undo deRecursos M inerais;

- CT-ESPA CIAL - Fundo Espacial de Ciência e Tecnologia;

- CT-INFO - Fundo deTecnologiadal nformação;

- CT-BIO TEC N O LO GIA - Fundo deBiotecnologia;

- CT-A GRO N EGÓ CIO - Fundo deA gronegócio;

- CT-AERO N ÁUTICO - Fundo A eronáutico;
- FUNTTEL - Fundo para o Desenvolvimento tecnológico das Telecomunicações;

- Verde-A marelo - Interação U niversidade-E mpresa.

Podem-secitar vários outros programas, como o daF undação do Banco do Brasil (F BB), que visa a "contribuir para a geração e/ ou desenvolvimento de tecnologia, apoiando financeiramente pesquisas técnico-científicas"; 0 do Programa de C apacitação de Recursos H umanos para o D esenvolvimento Tecnológico ( $R H A E$ ), que pretende o "aperfeiçoamento de recursos humanos, em todos os níveis, nas áreas consideradas prioritárias em termos do desenvolvimento tecnológico e industrial"; o do Programa de Desenvolvimento Tecnológico ( $F$ untec), que tem como objetivo "financiar os gastos com capacitação tecnológica da empresa eo desenvolvimento de produtos e processos" ${ }^{12}$ (1993) ${ }^{16}$ (1998).

N o entanto, éimportante frisar que "tal sistemática de fomento, embora similar à de outros países desenvolvidos, mais especificamente oS EU A, tem sido objeto de críticas não só dos pesquisadores etecnólogos, mas também de especial istas na questão" ${ }^{9}$ (1997, p.126).

U m exemplo disso estava naafirmação de Sicsú eA raújo ${ }^{17}$, que permanece atéhoje:

“U m problemaaser enfrentado nas estatísticas oficiaisé o conjunto de qualquer investimento na área de informática como sendo de $C \& T$. É incompreensível a alocação de orçamentos de órgãos cuja finalidade é normatizar rotinas e comprar equipamentos de informática para as demais instituições do estado, como sendo investimento em ciência etecnologia. C onfundese modernização da máquina administrativa com pesquisa e desenvolvimento" (1993, p.178).

O Programa Sociedade da I nformação, que está sendo desenvolvido pelo G TSI, ligado ao M CT, éum exemplo disso: a iniciativa éimportante, o programa sem dúvida devemerecer toda a atenção e colaboração da sociedade científica brasileira. C ontudo, o enfoque principal está direcionado àinfra-estrutura detelemática. $N$ ão quenão seja importante; ao contrário, sem infra-estrutura não é possível conceber uma sociedade baseada na informação e no conhecimento, mas a informação em si éque realmente é fundamental, o que de certa forma confirmaa preocupação deSicsú eA raújo. 
O ProgramadeA poio àC apacitação Tecnológica da Indústria (PACTI), subordinado ao CC T, tem como objetivo "apoiar, orientar e articular as ações relativas à capacitação tecnológica da indústria, visando a aumentar a competitividade dos bens eserviços produzidos no país" ${ }^{18}$ (1999, p.5).

O governo definiu como orientação estratégica do PAC TI para o período 1999/2002 "tornar a tecnologia uma prioridadenacional, não pela tecnologia em si, mas pela evidência dos benefícios que ela produz ou podevir a produzir para os cidadãos, os consumidores, o sistema produtivo nacional etoda a sociedade brasileira" ${ }^{18}$ (1999, p.6).

Paraisso, segmentou essetema em cinco opções estratégicas, conformesegue:

- "contribuir decisivamente para o aumento da competitividade de cadeias produtivas relevantes parao país;

- incrementar substancialmente a contribuição da capacitação edifusão tecnológica parao desenvolvimento regional elocal, em bases auto-sustentadas;

- intensificar a integração da capacitação tecnológica com a oferta de educação e a criação de novas oportunidades detrabalho;

- ampliar a disponibilidade de recursos humanos efinanceiros para a capacitação tecnológica das empresas e instituições nacionais;

- atuar intensivamentena integração deagentes e iniciativas no âmbito do PA C TI edestecom outros programas correlacionados ou complementares" ${ }^{18}$ (1999, p.6).

D estacar a primeira opção estratégica do PACTI éimportanteà medida que reafirma a importância de as cadeias produtivas brasileiras serem competitivas e, para queisso setornerealidade, a informação tecnológicaea indústria da informação devem estar consolidadas.

Para o período 2000-2003, o PA C TI pretende desenvolver "programas ditos de natureza'horizontal', isto é, programas que abrangem as empresas de uma forma ampla, sem aprofundar-se em setores preferenciais..." ${ }^{18}$ (1999, p.32).

D entre as várias ações inseridas no programa para o período anunciadas pelo M CT, destacam-se as seguintes:
- "ampliar as ações do TIB* , principalmente as voltadas para a superação de lacunas na oferta de serviços especializados, vis-à-visas demandas setoriais, com ênfa se especial em:

- apoiar a implementação do PN M - Plano N acional de M etrologia(aprovado pelo C onmetro* em dez./ 98);

- apoiar amodernização da normal ização técnica ea participação brasileira em fóruns internacionais denormalização;

- apoiar a ampliação das atividades de ensaios e de certificação, com ênfase nacertificação de produtos;

- apoiar a modernização da regulamentação técnica.

- ampliar as ações de fomento ao desenvolvimento e difusão das Tecnologias de Gestão para a Competitividade.

- ampliar as ações em parceria com aC N I** nos campos daPropriedade I ntelectual eTIB.

- buscar sintonia entre as ações da Secretaria eas ações e conceitos no âmbito do Programa Sociedade daI nformação" ${ }^{18}$ (1999, p.33-34).

C onforme apontado anteriormente, as ações perpassam a questão informacional. D aí a importância da informação no processo como um todo, ou seja, não existedesenvolvimento em $C \&$ T ou industrial, sem uma sólida indústriadainformação.

Por meio desses programas, o governo pretende viabilizar o desenvolvimento tecnológico das indústrias nacionais e, conseqüentemente, 0 crescimento econômico, assim como o avanço do Brasil peranteos países do primeiro mundo.

O Programa Sociedade da I nformação éa mais recente investidagovernamental epressupõeo uso da informação, das tecnologias da informação al iadas àtelecomunicação para o surgimento dessa sociedade denominada 'sociedade dainformação'.

* Tecnologia Industrial Básica (TIB)

${ }^{* *}$ Conselho $\mathrm{N}$ acional de M etrologia, N ormalização e Q ualidade Industrial (C onmetro)

${ }_{* * *}$ Confederação N acional da Indústria (CNI) 


\section{Marta Lígia Pomim Valentim}

O Programa definiu algumas linhas de ação, "que, por suavez, serão traduzidas em um conjunto de ações concretas, com planejamento, orçamento, execução eacompanhamento" ${ }^{19}$ :

1) mercado detrabalho eoportunidades;

2) universalização de serviços para a cidadania;

3) educação nasociedade dainformação;

4) conteúdos e identidadecultural;

5) governo ao al cance de todos;

6) $P \& D$, tecnologias-chave e aplicações;

7) infra-estrutura avançada e novos serviços.

Todas as estratégias governamentais planejadas com 0 intuito de desenvolvimento econômico e social são importantes na medida em que criam programas e ações direcionadas para diferentes setores que, posteriormente, viabilizam o seu próprio crescimento e competitividade. 0 desenvolvimento efortalecimento econômico do país, assim como sua maior competitividade no mercado internacional, propicia uma mel horia social significativa para a sociedade.

O Plano Plurianual 2000/2003, denominado 'Avança Brasil', I lançado em janeiro de 2000, apresenta al gumas diretrizes estratégicas, entre elas "C onsolidar a estabilidadeeconômica com crescimento sustentado; promover o desenvolvimento, gerando empregoseoportunidades derenda" 20 (2002), e conta com aproximadamente 365 programas governamentais.

N o entanto, observando a situação do programa hoje, verifica-seque dos “ 387 projetosiniciais, apenas 24 continuam sendo apoiados" ${ }^{21}$ (2002). N o orçamento daU nião, para 2003, verifica-se uma drástica redução: “apenas $\mathrm{R} \$ 7,2$ bilhões para investimentos, menosda metadedo que estava previsto, isto é, $\mathrm{R} \$ 18,1$ bilhões"22 (2002).

A nalisando o crescimento do PI B brasileiro (figura 3), percebe-se uma retração significativa, quando comparado a países como $\mathrm{C}$ hile, $\mathrm{C}$ oréia ou I I ndia, principalmente em um momento econômico nacional que exige competitividade diante da economia mundial.

L eite e $C$ ampanário ${ }^{23}$ afirmavam que, no contexto da política industrial ede $C \& \mathrm{~T}$, um dos segmentos quedeve ter grande distribuição de recursos dos programas gover- namentais, mas de médio e longo prazo, é a geração e aplicação do conhecimento científico e tecnológico (1995, p.9). Esteapoio governamental éprimordial, uma vez que a geração ea aplicação de conhecimento tanto científico e tecnológico quanto cultural é base para 0 desenvolvimento econômico, fator de competitividade industrial e, mais do queisso, fator de desenvolvimento social de um país. Por isso, existe uma necessidade premente de o governo rever a distribuição de recursos financeiros para essaárea.

A lém disso, a globalização da economia requer maior investimento em todos os níveis para dar maior competitividade aos segmentos econômicos e sociais do país.

A un ${ }^{24}$ afirma: " $O$ desenvolvimento de uma infra-estruturatecnológica é condição sinequa non paraquese tenha acesso à sociedade da informação. Porém, precisa-se pensar o nível de prioridade de infra-estruturana construção de políticas e programas informacionais" (1999, p.117).

A autora, em uma pesquisa desenvolvida sobre políticas deinformação, afirma:

"T odaaE uropa, com destaque para aF rança, A lemanha eR eino U nido, viveum processo de conscientização da necessidade do estabelecimento de uma política de informação que objetive colocar à disposição do maior número possível de cidadãos as informações governamentais, jurídicas, sociais, culturais, econômicas" 24 (1999, p.116).

Ci. Inf., Brasília, v. 31, n. 3, p. 92-102, set./dez. 2002 
Informação em ciência e tecnologia: políticas, programas e ações governamentais - uma revisão de literatura

0 governo ea sociedade cubanatambém discutem o estabelecimento deuma política deinformação para o país. $\mathrm{O}$ documento esclarece inicialmenteque a Política $\mathrm{N}$ acional de I nformação $\mathrm{C}$ ubana ${ }^{25}$ deve contribuir para:

- "E levar la eficiencia en la producción debienesy serviciosde información sati sfacer la demanda nacional einsertarnosen la industriainternacional;

- Facilitar que el proceso de descentralización se realice exitosamente, mejorando la toma dedecisiones, medianteel suministro deinformación pertinentey oportuna;

- Favorecer la gestión detodoslossectores, mediantela elevación desu competitividad» $(1998$, p.5).

0 primeiro item mencionado na proposta da política cubanatambém éfundamental para o Brasil, ou seja, fomentar a produção debens eserviços deinformação, para o crescimento da indústria nacional, assim como contribuir para o aumento da competitividadetecnológica das indústrias nacionais no cenário mundial.

D entre os nove principais objetivos citados pela política de informação cubana (1998, p.6) , éimportante ressaltar um deles:

'Alcanzar nivelesdeinserción ventajosa del paísen la industria internacional dela información, en lo referido a losbienesy serviciosdeinformación, a través desu comercialización externa, generando una fuente de di vi sas para el país por esta vía" 18.

A importância do estabelecimento de uma política de informação nacional éinquestionável. Evidentemente, - Brasil possui várias ações e programas governamentais quecontribuem paraa consolidação de uma políticanacional voltadaà informação. Entretanto, éfundamental uma política que privilegiea produção de bases de dados (conteúdos informacionais), primeiramenteporque no Brasil as informações ainda estão dispersas ou em núcleos de excelênciaeestão disponíveis de forma restrita aal guns segmentos produtivos da sociedade. Em segundo lugar porqueaglobalização exigeumacomercialização de duas vias, isto é, se as informações não estão consolidadas, como seráa troca? 0 u qual seráo poder detroca de informação do país? O Brasil será um eterno consumidor deinformações estrangeiras?

C riar uma estrutura nacional que priorizea informação para $C \& T$, por meio de subsídios àindústria da informação, do fomento aos produtores de bases de dados e do apoio àcomercial ização/ acesso a estas bases de dados pela sociedade, deveser prioridade na política de informação nacional.

D ocumento elaborado por uma das comissões da comunidade européia, mais especificamente a I nformation $\mathrm{M}$ arket $\mathrm{O}$ bservatory ( $\mathrm{M} \mathrm{O}$ ), direcionado à indústria da informação, enfatiza a importância de políticas para a área eapóia esta afirmativa em quatro razões fundamentais:

1) a produção de conhecimento dealto nível contribui ef etivamente para a economia e a sociedade;

2) a contribuição das publicações impressas para a balança comercial em termos monetários éalta;

3) os serviços de informação são vitais para a competitividade econômica européia, porquanto as indústrias os utilizam como componente paraobter eficiência e eficácia do setor;

4) os produtos multimídia são importantes segmentos industriais, com uma vocação genuinamente européia, e mesclam-se àidentidade cultural daregião ${ }^{26}(1995$, p.4) .

A s três primeiras razões apresentadas anteriormente como fundamento para o estabelecimento de uma política de informação podem também ser aplicadas no Brasil. A indústria da informação nacional deve ser consolidada, para que possa subsidiar todos os segmentos produtivos da sociedade. $M$ as, paraisso, aindústria da informação deve ser reconhecidacomo setor produtivo, como segmento econômico. Somentecom uma visão de cadeia produtivaéqueo setor poderárealmentereceber recursos do setor empresarial, bem como apoio governamental de forma eficiente.

A comunidade européia entende a contribuição da indústriada informação paraumaeconomiacompetitivae paraa consolidação daSociedade da I nformação.

No ano de 1990, M ontviloff ${ }^{27}$, por meio do Programa Geral del nformação daU nisist, elaborou um "manual sobreaformulação, aprovação, aplicação efuncionamento de uma política nacional de informação". Segundo ele:

"L a participación efectiva deun paísen el desarrollo desistemasy redesregionaleseinternacionalesdeinformación dependeen gran medida dela existencia deuna sólida infraestructura nacional deinformación. Esun hecho cada vez másaceptado queel desarrollo de una infraestructura de este tipo, y su contribución a la cooperación regional einternacional en el 


\section{Marta Lígia Pomim Valentim}

campo dela información, severá facilitado por la formulación y ejecución deuna política adecuada derecursosy serviciosde información en lospaíses partici pantesen la red" (1990).

Para M orales ${ }^{28}$, pesquisadoramexicana:

"C onvertir en una realidad el derecho a la información, debe haber una estrecha relación entrela sociedad y el Estado, tienen queinteractuar una y otro, para quedecara al futuro, ya muy próximo se tomen en cuenta los nuevos comportamientos, actitudes y valores de la sociedad globalizada y seadvierta el valor estratégico del conocimiento, la información y la lectura en el desarrollo y la democratización delas sociedadeslatinoamericanas" (1999).

D eacordo com a propostadePolítica $\mathrm{N}$ acional del nformação C ubana, o papel dainformação parao desenvolvimento nacional podeser resumido conforme segue:

"EI concepto dequela información constituyeun recurso nacional indispensablepara todos los programasy acti vidades nacionalesdedesarrollo, seafianza cada día más. Esconocido el efecto dela aplicación dela información en la productividad, su papel primordial en la planificación, en la toma de de decisionesoperativas y estratégi cas y en la solución delos múltiples problemas del desarrollo socioeconômico 25" (1998, p.12-13).

$\mathrm{N}$ a década de 80 , a Espanha játraçava diretrizes estratégicas, formuladas em um Plano $\mathrm{N}$ acional para a $\mathrm{D}$ ocumentação el nformação C ientífica eT écnica:

“1) D esarrolar al máximo la capacidad nacional deproducción y difusón depublicacionescientíficasy técnicas, haciendo de idioma español el instrumento máseficaz para la proyección dela cultura ydelaciencia española.

2) D esarrolar al máximo la capacidad nacional derecopi lación y tratamiento deinformación, potenciando losarchivos, las bibliotecas, losmuseosy loscentrosdedocumentación.

3) D esarrolar una infraestrutura de recuperación de información a nivel nacional einternacional.

4) Poner un gran énfasisen el desarrollo delosrecursoshumanosnecesariospara la prestación delosserviciosdeinformación ydocumentación.

5) Sensibilizar a la sociedad en el valor dela información y de losserviciosdeinformación y documentación.
6) Promover la realización deacciones deinvestigación y desarrollo detipo finalista orientadas a la amplicación y produción derecursosdeinformación propriosy al desarrollo dela necesaria infraestrutura dedistribución y difusión delos serviciosy productosquedeellospueden derivarse.

7) O rientar lasaccionesdecooperación com I beroamérica en materia deinformación y documentación.

8) E stablecer una estructura quedesarrollelasactividadesconsultivas y de fomento necesarias para la formulación y cumplimiento dela política deinformación y documentación.

9) Recomendación final: L a C omisión considera quela Administración del E stado debeanalizar urgentementeeste sector deactividad de la información y documentación, y formular sin demora su política de desarrollo» ${ }^{29}$ (1993, p.30-32).

Tanto a primeira quanto a terceira diretriz chamam a atenção. $N$ a primeira, a comissão detrabal ho sugere que a produção ea difusão da produção técnico-científica são um instrumento eficaz paraa projeção da culturaeda ciência espanholano mundo. C omprovadamente, nas duas últimas décadas, a cultura e a ciência daquele país têm se destacado deforma muito eficaz.

N o caso da terceira diretriz, desenvolver uma infra-estrutura de recuperação da informação em nível nacional einternacional também éfundamental para o Brasil, ou seja, a consolidação da indústria da informação, por meio das bases de dados. É importantelembrar que estedocumento foi elaborado na décadade 80.

O plano deinformação edocumentação (I + D) propunhatambém a formulação de políticas de informação e documentação, segmentadas em cinco programas:

- "Programa N acional deTecnología dela I nformación y de lasC omunicaciones

- Programa $\mathrm{N}$ acional del nformación para la I nvestigación C ientífica y el D esarrollo Tecnológico.

- Programa $\mathrm{N}$ acional de Interconexión de Recursos Informáticos(IRIS).

- ProgramaSectorial dePromoción G eneral del C onocimiento.

- Plan E lectrónico el nformático N acional (PEIN ) »29 (1993, p.35). 
Informação em ciência e tecnologia: políticas, programas e ações governamentais - uma revisão de literatura

D amesmaformaquepaíses desenvolvidos egrandes blocos econômicos ou países quebuscam o desenvolvimento, a informação e a sociedade da informação devem ser entendidas como insumo eestrutura para o desenvolvimento de uma nação. Sebastian ${ }^{30}$ afirma que:

“El perfil político dela información está siendo cada vez más intenso, hasta el punto de que podemos establecer una clasificación delos paísesno sólo por su capacidad económica ( ricosy pobres) sino por su capacidad informativa. Por ejemplo, lospaíseslatinoamericanossepueden induir dentro delosinfopobres, si bien escierto queexisten al gunastentativas depolítica deinformación abocadasa recuperar su autonomía respecto de países como E stados U nidos, que aúna la política de desarrollo tecnológico y delastelecomunicacionescon su gran industria de la información que sobrepasa susfronterasal mundo iberoamericano. N o obstante, las autopistas dela información, y especialmentel nternet, como principal pilar del desarrollo deesta nueva soci edad, está creciendo másdeun $100 \%$ anual en L atinoamérica, y el número deusuariosseha triplicado en el último año16. G arantizar el acceso a la información por todoslosciudadanosdel mundo, incluidoslos tecnológicamentemarginados" (2000, p.27).

E m resumo, observa Schwartzman ${ }^{31}$ : "A s políticas destes últimos 25 anos podem ser entendidas como desdobramentos das mudanças ocorridas na sociedade e na economiabrasileiras nas décadas anteriores" (1995, p.13). 0 país precisa estar em sintonia com as mudanças provocadas pelaglobalização ebuscar a estruturanecessária para o quepretendeser no futuro como país.

Tundisi ${ }^{32}$ expõesuaopinião:

"A pós 50 anos de um sistema de apoio à ciência e tecnologia, que começou formalmente em 1951, com a implementação do Conselho $\mathrm{N}$ acional de Pesquisa (C N Pq), da F apesp, em 1961, e da Finep, em 1973, o B rasil passa por umafase detransição na formulação de políticas públicas de apoio ao desenvolvimento com base em ciência e tecnologia. A constituição desses fundos sinaliza que o governo federal considera estratégico 0 apoio à ciência etecnologia, à aplicação da capacidade de produzir conhecimento eàaceleração das interações universidade-indústria com o apoio decisivo à inovação (...) A criação de fundos setoriais deve resolver um dos problemas mais cruciais do financiamento, queéa falta de continuidade e a instabilidade na al ocação de recursos para o fomento à C \& T" $(2000$, p.7) .

A política para $C \& T$ do país tem sido sistematicamente apoiada por diferentes governos, no entanto falta ao país maior envolvimento do setor privado como investidor na produção deconhecimento. Esseaspecto fundamental para o desenvolvimento do setor deinformação no país precisa derecursos bem direcionados, bem como osprogramas de apoio devem oferecer linhas de fomento de forma desburocratizadae claramente direcionadaà essaárea.

A rtigo aceito para publicação em 24-04-2002

\section{REFERÊNCIAS}

AUN, M. P. A construção de políticas nacional e supranacional de informação: desafio para os Estados nacionais e blocos regionais. Ciência da Informação, Brasília, v. 28, n. 2, p. 115-123, maio/ago. 1999.

BARRETO, A. de A. Infor mação e transferência de tecnologia: mecanismos e absorção de novas tecnologias. Brasília : IBICT, 1992. 64 p.

BASTOS, E. M. C. O sistema brasileiro de C\&T e o novo paradigma de desenvolvimento econômico. Revista de Administração Pública, Rio de Janeiro, v. 31, n. 3, p. 116-132, maio/jun. 1997.

BRASIL. Ministério da Ciência e Tecnologia. PADCT III: documento básico. Brasília, 1998. Disponível em: <http:// www.mct.gov.br/prog/padct_III/msof0.pdf>. Acesso em: 22 maio 2002 .

Relatório de atividades 1999: diretrizes para 2000. Brasília 1999. $35 \mathrm{p}$

Ministério do Planejamento. PPA/1996/99:

investimentos e ação governamental. Brasília, 1996. Disponível em: <http://www.planejamento.gov.br/

planejamento_investimento/conteudo/PPA1996/

investimentos.htm>. Acesso em: 22 maio 2002.

PPA/2000/03 - Avança Brasil: 365 programas e foco no cidadão. Brasília, 1999. Disponível em: <http://

Www.planejamento.gov.br/planejamento_investimento/conteudo/ PPA2000/365_programas.htm>. Acesso em: 22 maio 2002.

CNPq (Brasília, DF). A instituição. Disponível em: <http:// www.cnpq.br/sobrecnpq/informaçõesinstitucionais/index.htm>. Acesso em: 28 maio 2002.

COUTINHO, L. G.; FERRAZ, J. C. (Coord.). Estudo da competitividade da indústria brasileira. 3. ed. Campinas : Papirus/ Editora da UNICAMP, 1995. 510 p.

CUBA. Ministerio de Ciencia, Tecnologia y Medio Ambiente. Política nacional de información. Habana, 1998. 22 p.

EUROPEAN COMMISSION INFORMATION MARKET OBSERVATORY. The role of the content sector in the emerging information society. Luxembourg, 1995. 19 p.

FINEP (Brasília, DF). A empresa: diretrizes estratégicas. Disponível em: 〈http://www.finep.gov.br/empresa/diretrizes.asp> Acesso em: 28 maio 2002.

FURTADO, A. (Coord.). Capacitação tecnológica, competitividade e política industrial: uma abordagem setorial e por empresas líderes. São Paulo : IPEA, 1994. 133 p. (Texto para discussão, 348).

GUIMARÃES, R. Avaliação e fomento de C\&T no Brasil: propostas para os anos 90. Brasília : MCT/CNPq, 1994. 178 p. (Acompanhamento e avaliação de C\&T). 


\section{Marta Lígia Pomim Valentim}

IBICT (Brasília, DF). Guia de fontes de financiamento à ciência \& tecnologia. 6. ed. Brasília, 1993. 197 p.

$$
\text { 10. ed. Brasília, } 1998 .
$$

LEITE, C. A. G.; CAMPANÁRIO, M. de A. Novo contexto de política industrial e de C\&T. Brasília : MCT, 1995. 11 p.

MARQUES, P. Modernização do Brasil: dilemas e perspectivas. São Paulo : IEA/USP, 1994. 53 p. (Política científica e tecnológica, 18).

MONTVILOFF, V. Políticas nacionales de información: manual sobre la formulación, aprobación, aplicación y funcionamiento de una política nacional sobre la información. París : UNESCO, 1990. 169 $\mathrm{p}$.

MORALES, E. El derecho a la información y las políticas de información en América Latina. In: IFLA COUNCIL AND GENERAL CONFERRENCE, 65th, 1999, Bangkok. Anais... Bangkok, 1999. Disponível em: <http://www.ifla.org/IV/ifla65/papers/056-137s.htm>. Acesso em: 03 jul. 2002.

RANGEL, A. S. Diagnóstico de C\&T no Brasil. Brasília : MCT, 1995. $13 \mathrm{p}$.

ROSSI, C. Orçamento 2003: apenas R\$ 7,2 bilhões para investimentos - menos da metade do que estava previsto (R $\$ 18,1$ bilhões). Folha de São Paulo, São Paulo, 01 set. 2002.

SANT'ANA, M. A. de A. et al. Desempenho industrial e tecnológico brasileiro. Brasília : UnB, 1990. 277 p.
SCHWARTZMAN, S. et al. Ciência e tecnologia no Brasil: uma nova política para um mundo global. In: (Coord.). Ciência e tecnologia no Brasil: política industrial, mercado de trabalho e instituições de apoio. Rio de Janeiro : FGV, 1995. p.1-59.

SEBASTIAN, M. C. et al. La necesidad de políticas de información ante la nueva sociedad globalizada: el caso español. Ciência da Informação, Brasilia, v. 29, n. 2, p. 22-36, maio/ago. 2000.

SICSÚ, A. B.; ARAÚJO, T. B. de. Modelo de informação sobre gastos dos estados em C\&T: considerações metodológicas. Ciência da Informação, Brasília, v. 22, n. 2, p. 177-180, maio/ago. 1993.

SOUZA, J. de. Avança Brasil começou com 387 projetos; hoje move apenas 24. Folha de São Paulo, São Paulo, 02 set. 2002.

TAKAHASHI, T. (Org.). Sociedade da informação no Brasil: livro verde. Brasília : MCT, 2000. 203 p.

TUNDISI, J. G. Novas perspectivas e desafios: os fundos setoriais para a pesquisa podem transformar o país. Pesquisa FAPESP, n. 52, p. 7 , abr. 2000 .

VIEIRA, A. da S. Monitoração da competitividade científica e tecnológica dos estados brasileiros: um instrumento de macropolítica de informação. Ciência da Informação, Brasília, v. 28, n. 2, p. 174189, maio/ago. 1999.

VILLAVERDE, A. P. Política de información y documentación en España. Ciencias de la Información, Havana, v. 24, n. 1, p. 29-42, mar. 1993

WEISS, J. M. G. Ciência e tecnologia no contexto da globalização: tendências internacionais. Brasília : MCT, 1995. 23 p. 